\title{
Faultlines in Mine Closure Planning in a Developing Country Context
}

\author{
D. Limpitlaw University of the Witwatersrand, South Africa
}

M. Hoadley South Africa

\section{INTRODUCTION}

The global debate on the contribution of mining to sustainable development reached a high point with the publication of the report of the Mining, Minerals and Sustainable Development project (MMSD, 2002) and the subsequent deliberations at the World Summit on Sustainable Development in Johannesburg in 2002. This exposed a number of discontinuities between stakeholders. One of these is the difference between the conservation and stewardship focussed, northern country perspective, and the development focussed, southern country perspective. In the former, the term sustainability is often employed, while in the latter, the preference is for the term sustainable development, with emphasis often on the second word. The sustainability mindset is exemplified by organisations such as the Natural Step (see www.naturalsep.org) which argue for a target of no net transfer of material from the geosphere to the biosphere. This perspective is defensible in societies where most people have access to safe water and sewerage, live above the bread line and where what natural land cover remains is highly altered. The perspective is not as acceptable in societies where substantial infrastructural construction programmes are required to reduce mortality, morbidity and poverty. For such societies, substantial progress in development needs to occur before longterm sustainability can be achieved. This development obviously has to occur within the paradigm of sustainable development. In the developing societies of Southern Africa, mining can play an important role in providing the economic development required to reduce poverty.

The contribution of mining to sustainable development must be considered and optimised throughout the mining lifecycle, from exploration through to post-closure, but it is during and after the closure phase of the mine's life that the greatest test of this contribution occurs. Mines close for a number of reasons, ranging from depletion of ore reserves, changes in market conditions through to environmental degradation, social upheaval or political instability. Several closure scenarios have been identified (Peck et al., 2005), including:

- Ordered advance and completion - this is the best case scenario; integrated mine planning is followed from the pre-feasibility design up to depletion of the ore body, including decommissioning of infrastructure and rehabilitation of the mine site, resulting in physical and chemical stability of the site and alternative livelihood options for employees and the surrounding community.

- Strategic revision of final operational period - desirable post- mining outcomes (such as those described above) are not originally included as objectives in mine plans, but are retro-fitted in the final years of the operation's life; the ease, effectiveness and efficacy with which these objectives are achieved are invariably lower than in the above case, but desirable outcomes can still be achieved.

- Ordered retreat - mines are sometimes forced to close before their planned closure date due to changes in the viability of their operations; where adequate planning and provision for closure has occurred, adequate decommissioning and rehabilitation programmes can still be implemented.

- Retreat in disarray - mines that are forced to close prematurely, without adequate closure planning and provisioning, invariably leave behind unrehabilitated surfaces and other mining legacies such as economic collapse and unemployment; this scenario may result in legal proceedings being brought against the company by the authorities to recover the costs of adequate rehabilitation works.

- Dereliction of duty - in this case, companies engage in asset stripping to remove value that could be used to offset un-provisioned rehabilitation costs; criminal proceedings may be instituted by the state in extreme cases. 
Peck argues that it is only the first three cases that are acceptable. The last two cases result in heavy burdens on the state, often resulting in mining legacies in capacity-limited Southern Africa. Namibia, for example, has a sound policy document on environmental management, the 1995 Environmental Assessment Policy (see MET, 1995). In 2006, new mine development in that country was still not legally required to comply with this policy as the enforcing legislation in the Environmental Management Bill has not yet been passed into law. This effectively means that irresponsible operators have minimal controls on their provisions for impact mitigation and mine closure. Other countries in the region also experience problems: in South Africa, environmental management and mitigation of social impacts are well provided for in policy and legislation, but monitoring and enforcement limitations within the inspectorate limit the efficacy of the state. To make matters worse, the critical need for rapid service provision in rural areas has resulted in calls for relaxation of environmental regulations as these are seen as impeding development.

\section{THE CURRENT LANDSCAPE - MINERALS BOOM}

In the last few years, global demand for commodities has outstripped supply, leading to a reduction in stockpiles and a concomitant increase in prices. This has led to renewed interest in mineral properties around the globe. Southern Africa has long been a highly prospective terrain and this renewed interest in mining has lead to a 'gold-rush' across countries and commodity classes. The dramatic increase in the price of uranium oxide, for example, has resulted in a flurry of prospecting applications in Namibia's Erongo Region. This region has seen much uranium prospecting activity over the years, but since the mid-seventies Rössing Uranium has been the lone operator in Namibia. In 2005, construction commenced on a new mine, Langer Heinrich Uranium, and this is likely to be followed by at least another three new mines. An article in a Namibian newspaper, Die Republiken, (published on 15 June, 2006) identified another seven sites that are in various stages of investigation. The closure of a substantial mine, like Rössing Uranium, would have a serious impact on the local economy, but the growing eco-tourism sector could generate alternative livelihoods. The real danger lies in the closure of a group of mines close together in both time and space. The existing and developing mines in the region are within $100 \mathrm{~km}$ of each other and have expected minimum mine lives of around 10 years. Should commodity prices experience a sudden down turn, large-scale, simultaneous closure could occur, leaving thousands of people destitute. Variable quality of mine closure planning at some sites could also result in extensive environmental liabilities on early closure, burdening the state and resulting in destruction of the sensitive desert ecosystem that is the foundation of the region's ecotourism industry.

Current good practice in mine planning requires the compilation of an environmental impact assessment (EIA) and an environmental management plan (EMP). This is also mandatory in most jurisdictions. The EIA must identify and propose mitigation measures for the significant impacts arising from the mine. Where one operation occurs in relative isolation, a project EIA can achieve this. Where a number of operations, at different stages in their life-cycles, occur in close proximity, project level EIAs need to be framed in the context of a larger strategic environmental assessment (SEA) and an integrated development planning framework (IDP). In many developing countries, SEAs and IDPs do not exist. This means that closure plans drawn up by one mine may work against those of another. Wilderness and conservation may be the postmining land use planned by one operator, while the adjacent operator may be working towards industrial use. Carefully crafted, long term plans to wean a dependant community of mine support in time for closure may be destroyed by well meaning, but disastrous, cheque-book philanthropism of a new arrival.

In Southern Africa a broader framework for sustainable development, or even just for development in some instances, is frequently absent. Under these conditions cooperation and collaboration between developers (in this case mining companies) is essential. Such voluntary initiatives were identified by the MMSD project as a potentially important intervention for promoting sustainable development (Walker and Howard, 2002). As strengths of these initiatives, MMSD included characteristics such as efficiency, the creation of savings for governments, the highlighting of the SD business case and the fact that the initiatives are supported by a broad range of drivers that are not dependant on regulatory demands. When considering how voluntary initiatives can deliver improved performance, particularly in a capacity constrained regulatory environment, these characteristics are important. 
Where no SEA or IDP exists, the only effective way to ensure that closure plans for one operation do not undermine or work against the closure plans of another, or the development plans of the local authority, is through regular contact and discussion to promote cooperative planning in such non-competitive areas.

On the negative side, MMSD reported that there is only poor evidence of broad effectiveness in delivering environmental improvements, that selective adoption of an initiative by industry can result in "free-riders" this is compounded by the fact that the voluntary approach becomes less attractive once the profitable, easy and inexpensive improvements are taken up and more difficult changes are required - and the fact that such initiatives can be seen by government as a substitute for regulation and can result in the dismantling of regulatory capacity. This last point is important in a developing country context as the involvement of the state is critical for long-term planning and sustainability after closure. The state is the ultimate inheritor of mining landscapes and infrastructure and has the responsibility to ensure that any projects or infrastructure can be operated after the operation closes.

\section{CLOSURE PLANNING FAULTINES IN A DEVELOPING COUNTRY CONTEXT}

Southern Africa epitomizes the paradox of "poverty in the midst of plenty" in that the region has great mineral wealth, but is one of the poorest regions on the globe, with the average daily per capita income being just above US\$2. Although the MMSD project concluded that the minerals sector has the greatest potential of any sector in the region to contribute to development and poverty alleviation, significant signs of such positive impacts are rare. On the contrary, the impacts - health, social and environmental - that mining generates are usually borne by local communities, already poor. For communities, especially remote and isolated ones, the opportunity for social, economic and infrastructure development is usually unique, but often not realised. Communities frequently end up poorer at closure than they were before mining commenced.

\subsection{Current Areas of Poor Practice in Southern Africa}

Closure planning is not foregrounded in initial mine planning. Environmental and social assessments as currently practiced in many parts of Southern Africa tend to focus on the impacts arising from the construction and operational phases of the mine rather than those prevalent after closure. In the social sphere, much of the training and skilling of communities, for instance, is focussed on gaining access to mine contracts during the life of the mine. The more difficult question of post-mining livelihoods is often left to last months or years of the operation's life. Mitigation plans are frequently framed in terms of the operating impacts of the mine. Closure impacts are seen as being dealt with adequately in the EMP drawn up primarily for these operational impacts. The mismatch between operational phase and closure impacts is compounded by the fact that the socio-political environment in which a mine operates is dynamic and may have changed dramatically by the time closure occurs.

Sustainable development needs to be clearly defined within the relevant context and against social and environmental baseline studies. Without such studies there is no accurate way of identifying community needs or of monitoring environmental impact during operation. Sound baseline data also identifies the structures within a community that have contributed to its survival/sustainability/viability before mining started, so that these can be used as a basis for development. These will include social networks and cultural values, and should be captured as the information will facilitate the mitigation and monitoring of social impacts. Many project developers, not just mining companies, have no clear idea of the community they are working with and government departments are often unable to provide the most basic information, such as population numbers. Baseline information is also essential for establishing end land-use, which is one of the aspects that must be decided on at the start of the life-of-mine.

In most cases, communities remain marginalized from important decisions about mine development, including whether mining projects will be permitted. Community consent for mineral projects is seldom sought and communities are not routinely involved in mine management, oversight, environmental monitoring and other aspects that will affect the community. Stress is laid, quite rightly, on the extent to which communities share in the benefits of local operations, but this is not enough. Communities need to be included in decision making throughout the life of the project, and should be able to decide whether the 
project is initiated, and if so, under what conditions. This amounts to an acknowledgement of the community's status as an equal partner, without which it is likely to remain a passive recipient of the mining company's development initiatives. In most cases, the mining company is the active partner in project development. Government, which is responsible for legislation, and thus a key stakeholder, is usually less actively involved, largely due to a lack of skills and resources. Historically, communities have not been regarded as the best judges of their own development needs, and this practice continues. The underdeveloped status of many communities and the low levels of literacy and education are used as indicators of their inability to contribute meaningfully to mine planning. The failure to empower communities with knowledge and choice skews the balance of power and communities are frequently acted "on" instead of acted "with". This is compounded by the remoteness of central and regional government, which leads to vulnerability of the community to political and personal agendas.

There is a real need to define exactly what the term "consultation" includes. In most cases, communities are told about the operation, and their views are asked, but very often ignored. Too many communities are not aware of their rights, nor are any attempts made to make them aware. They are at the mercy of the mining company and, very often, self-appointed community representatives with their own agendas. When decisions are made about development, it is frequently the convenience of other stakeholders, rather than the needs of the community, that is the decisive factor. Arguments of logistics and economics are used to override the very real needs of a community. Interests of mine development partners, such as bulk water utilities, energy utilities, government education and health departments often dictate what sort of infrastructure is seen as sustainable post closure. Consultation effectively becomes a one-way process.

\subsection{Faultlines in "Best Practice" in a Developing Country Context}

The question of the extent of a mining company's obligations to local communities is difficult to answer. These obligations are dictated by the size of the operation, the extent of the impacts, the value of the orebody, the estimated life-of-mine and numerous other factors. Current thinking on infrastructure development is that it should be limited because communities cannot maintain these physical assets after closure, and schools and clinics are frequently handed over to government departments which don't have the capacity or resources to maintain them. This approach needs to be rethought. A significant number of mining operations are located in un- or underdeveloped rural areas, on land occupied by indigenous people ${ }^{1}$. In such areas, mining companies perforce take over the government function of infrastructure provision, such as roads, rail links, telecommunication, piped water and electricity. Such infrastructure is of significant benefit to both the community and the state, the latter being relieved of the financial burden of service provision to remote areas. Although this infrastructure is primarily for the purposes of production, it will have a considerable impact on the economy, culture and activities of the community. The mine has an obligation to ensure that the community has the necessary skills and resources to maintain this infrastructure after closure. The community's lifestyle will have changed significantly, and the collapse of infrastructure on which it has become dependent, socially and economically, will lead to the collapse of community structures and be a barrier to its survival as a sustainable community.

The argument that government departments cannot maintain infrastructure for social services is a serious indictment of national governments, as services such as health care and schooling are basic human rights, and governments are obliged to provide their citizens with access to these, even more so when they have been relieved of the initial financial burden of providing the infrastructure. Where the need for such facilities has been identified, companies should lobby government to guarantee the continuance of these services.

The Erongo Region in Namibia is experiencing a boom in uranium mining as a result of the phenomenal increase in the price of the commodity. Low-grade deposits have become viable, and the investment regime in Namibia has made the country an attractive investment haven for many mining companies, the vast majority foreign and junior companies. These companies are free of the (usually) strict control of mining activities in their own countries and disturbing tendencies to exploit the liberal environment in Namibia are

\footnotetext{
${ }^{1}$ For example, Moody, in Keenan et al. (2003) estimates that by the year 2020, 60 to 70 percent of world copper production will take place in the territories of indigenous people.
} 
manifesting themselves in some poor EIA's and development that shows little regard for the natural environment. Probably their greatest failure to ensure that they contribute to development and poverty alleviation in Namibia is their lack of community consultation, in some cases even a failure to identify such communities. There are indications that mining companies from countries with extremely lax mining regimes are also focusing on Namibia, and the scenario for sustainable development could be bleak. The onus here is clearly on the Namibian government, which in terms of its constitution, has undertaken to actively promote and maintain the welfare of the people by adopting policies aimed at the maintenance of ecosystems, essential ecological processes and biological diversity of Namibia and utilisation of living natural resources on a sustainable basis for the benefits of all Namibians, both present and future. The Namibian Environmental Assessment Policy also requires full consultation of all interested and affected parties but, as mentioned previously, enforcing legislation has not yet been passed.

Developing economies in Southern Africa all have poverty alleviation and rural development as key foci of their development agendas. Governments must, accordingly, ensure that resources and skills are in place to monitor and evaluate the impacts caused by mining operations, environmental, social and economic, and to be an active partner in the minimisation or optimisation. Governments are selling the nation's resources for short-term gain, and scarce resources (such as water) are being made available to foreign operations and denied to local communities.

In the rush to promote minerals development in Southern Africa, livelihoods are being destroyed, with little chance of these being replaced. In a conservancy in Namibia, set aside for subsistence conservation activities of the local community, just two prospective mining operations will occupy about $13 \%$ of conservancy and communal land. This land is arid and unsuitable for agriculture, but is suitable for game, one of the uses which is envisaged by the Namibian legislation with regard to conservancies. Some operations are likely to have severe negative impacts. One mine will be situated close to a major tourist attraction in the area. There will be light, noise, dust and visual pollution, the main access road will be one used by the community, its livestock and children and travellers across the desert. The operation will be situated close to where the community lives. These impacts are going to be inordinately difficult to avoid and mitigate, and closure will in all likelihood be a non-event for the community as it will already have been devastated. Of further concern is the fact that these two operations will not be the last to gain a licence to operate within the Conservancy. It is probable that the Conservancy will increasingly lose land to mineral exploitation, thus negating the purpose for which conservancies are established.

In negotiations around mineral development, governments are the regulatory agency. They seldom have the capacity and resources to become active partners. Communities are not fully consulted, and such consultation frequently does not extend beyond the initial phases of mining. Because of their lack of involvement, communities tend to see mining companies as sources of unlimited funding, and their expectations are disappointed rather than managed. The question is always: what can the mine do for this community? Seldom are the questions concerned with what the government should be doing, or with what the community can do for itself. Inherent in this situation is dependency on the mining company, and this has proved to be one of the social legacies which most constrain community development after closure.

A very relevant question is: how can a mining company contribute to development and poverty alleviation, but this question should be extended to include governments and communities themselves. Cooke and Limpitlaw (2003) cite the two main drivers of change in closure practice as industry and government, with organised labour playing a pivotal role on occasions. They state further that "Communities may also strongly influence closure, but in general, industry and government drive the negotiations." This last sentence foregrounds one of the constraints on successful closure. There should be nothing tenuous or uncertain about the role that communities play - they should be full partners and equal drivers in negotiations. When mining goes the company is no longer there. Government should be there as the co-driver, with the community, of the sustainable development trajectory, but it frequently is not. Unless the community has been included in the development process during the life of mine, it will not be able to ensure its own sustainable development.

Modern mining is capital-intensive, as opposed to labour-intensive. Few local people are hired at mines and skills are generally brought in from elsewhere, often expatriates. Mines should thus not be seen as creating large-scale direct employment, but rather contributing to economic development through the growth of 
secondary industries, service providers and furthering local economic development by slotting development plans into local, regional and national growth strategies.

Development does not take place in a vacuum, but within a series of nested government development agendas which contribute, on an increasing spatial basis, to the national development agenda. These development agendas need to be aligned to achieve the overall aim of sustainable development for the entire country. National development agendas are long-term and look at desired scenarios decades in advance, usually on an incremental basis of five- or ten-year plans. This system optimises sustainable development, and mining companies should align their development initiatives with national (and concomitantly with regional and local) development plans. Such alignment is constrained by a number of factors. Mining companies value the positive public image which can result from short-term, high impact, local projects, done on an individual basis. In some cases, companies are not aware of what development programmes are, particularly at the level of local economic development. Consultation in formulating these plans frequently does not extend to mining companies, and, even in areas which are endowed with mineral resources, and where mining operations already exist, municipal IDPs, in a large number of cases, do not refer to mining and the role it could play in development. In South Africa, such alignment is mandated. The South African Mining Charter requires the following question to be answered: "Has the company co-operated in the formulation of integrated development plans and is the company co-operating with government in the implementation of these plans for communities where mining takes place and for major labour sending areas?" Such a clearly articulated directive for social development is rare in Southern Africa, and its value lies in the obligation it places on mining companies to align their development projects with a more inclusive agenda, and the obligation it places on local and regional authorities to create the regulatory environment which makes such alignment possible.

\section{CONCLUSION}

By the end of the last century, the Zambian Copperbelt, responsible for the bulk of that country's copper production and economic activity had a population density of 37 people per square kilometre, up from the historically sustainable density of 4 people per square kilometre (Limpitlaw, 2003). When these mines were established, there was no planning for closure. As this inevitability draws closer, the plight of the million+ mining-dependant people living in the cities becomes more acute. In this context, mines cannot afford to only invest in restoration of the natural landscape by rehabilitation and complete removal of mining infrastructure - best practice in many developed societies. These operations need to ensure that, in addition to rehabilitating the environment to a sustainable state, they leave behind useable infrastructure and capacitated communities. The same is true for the new uranium operations in Namibia. Without this planning, dependant communities will not only fall back into poverty, but may be completely destroyed, thereby obliterating whatever economic benefit may have been generated by the mine. In a developing country context, the infrastructure created by the mine may provide a unique opportunity for development and, when environmental variables permit, it should be regarded as an asset.

Meeting the additional development demands placed on mines at closure in developing contexts is made more difficult by short-termism on the part of developers and some regulators. Governments often focus on project foreign exchange earnings, tax and royalty revenues and short term economic growth when authorising new operations. These factors are incentives as they make election promises more achievable. The horizon for such decisions is frequently the next general election. Mining companies also fall prey to this type of decision making. Blinded by short-lived upturns in commodity cycles or, as in the case of some juniors, by the prospect of on-selling mineral tenements, long term risks are not properly evaluated, often with serious consequences for closure.

Mines cannot plan for closure, nor can they ensure that their impacts are minimised, in isolation. SD, by its very nature, requires participation and consensus of many diverse parties. Even a rigorous EIA and closure plan that is pre-occupied with the impacts arising from the mine and does not link in with other operators or local authorities, will not make an optimal contribution to the sustainable development of the region in which the mine occurs. 


\section{REFERENCES}

Cooke, J.A. and Limpitlaw, D. (2003) Post-Mining Site Regeneration: Review of Good Practice in South Africa, unpublished report for the Global Mining Consortium, Global Centre for Post-Mining Regeneration, Cornwall, UK.

Keenan, K., de Echave, J. and Traynor, K. (2003) Mining and Communities: Poverty Amidst Wealth, International Conference on Natural Assets, Conference Paper Series No. 3. Political Economy Research Institute and Centre for Science and Environment.

Limpitlaw, D. (2003) An Assessment of Mining Impacts on the Environment in the Zambian Copperbelt, Ph.D. Thesis submitted to the Faculty of Engineering and the Built Environment, University of the Witwatersrand, Johannesburg, 299 p.

MET (Ministry of Environment and Tourism) (1995) Environmental Assessment Policy, Directorate of Environmental Affairs, Ministry of Environment and Tourism, Windhoek, 15 p.

MMSD (Mining, Minerals and Sustainable Development) (2002) Breaking New Ground, Mining Minerals and Sustainable Development, The Report of the MMSD Project, International Institute for Environment and Development and the World Business Council for Sustainable Development, Earthscan Publications, 441 p.

Peck, P., Balkau, F., Bogdanovic, J., Sevaldsen, P., Skaalvik, J.F., Simonett, O., Thorsen, T.A., Kadyrzhanova, I. and Svedberg, P. (2005) Mining for Closure: Policies and Guidelines for Sustainable Mining Practice and Closure of Mines, UNEP, UNDP, OSCE \& NATO, 97 p.

Walker, J. and Howard, S. (2002) Finding the Way Forward: How Could Voluntary Action Move Mining Towards Sustainable Development? International Institute for Environment and Development and WBCSD, London, $58 \mathrm{p}$. 